\title{
Formation and Segregation of Heterozygous Diploids between a Wild-Type Strain and Derivatives of High Penicillin Yield in Penicillium chrysogenum
}

\author{
BY K. D. MACDONALD, J. M. HUTCHINSON AND W. A. GILLETT \\ Microbiological Research Establishment, Porton, Salisbury, Wiltshire
}

(Received 14 July 1963)

\begin{abstract}
SUMMARY
Heterozygous diploids were produced between a wild-type strain of Penicillium chrysogenum and two strains derived from it. The derived strains had been isolated after several and latterly divergent selection steps, selection being made at each step for higher penicillin yield. The diploids had penicillin titre values near that of the wild-type strain so that mutations for increased penicillin production which had been accumulated in the derived strains appeared in the main to be recessive. First-order segregants isolated from the heterozygous diploids were in each case predominantly of one phenotype.
\end{abstract}

\section{INTRODUCTION}

Applications of parasexuality in Penicillium chrysogenum include not only the possibility of breeding for increased penicillin yield per se but also for other desirable characteristics which might indirectly have a favourable effect on penicillin production. Backus \& Stauffer (1955) carried out a mutation and selection programme at Wisconsin where strains of $\boldsymbol{P}$. chrysogenum were selected for increased penicillin production. They reported that there was a tendency towards a progressive decrease in the vegetative and reproductive vigour of strains as their ability to produce antibiotic increased, although they emphasized that this was not an infallible criterion for selecting isolates of high penicillin yield. If it were, then the inference would be that decrease of vigour in any particular case was most likely due to the same mutation which led to an increase in antibiotic yield. While pleiotropic mutations of this sort could occur it is also possible that in the development of the Wisconsin series of strains over many steps there could be a gradual accumulation of mutations which affected the general vigour of the organism but which were independent of mutations leading to increased antibiotic production. Mutations affecting vigour or other cryptic mutations which might be amassed during a long selection programme might have deleterious effects on the expressions of mutations for greater penicillin yield. If heterozygous diploids could be made between some of the Wisconsin isolates of high penicillin yield and their more vigorously growing ancestors, then recombinants might be isolated which combined desirable traits separated in the parents (Pontecorvo, 1954).

The Wisconsin series of strains, and probably all strains of Penicillium chrysogenum used for the production of penicillin on an industrial scale, originated from the wild-type strain, NRRL 1951 (Raper \& Alexander, 1945). Apart from offering possibilities for use as a parent as discussed above, this strain therefore could also 


\section{K. D. Macdonald, J. M. Hutchinson and W. A. Gillett}

serve as a tester strain to discover the degree of dominance or recessiveness of mutations leading to increased penicillin production. The latest strain of the Wisconsin 'nitrogen mustard' line and the highest penicillin producer in this series was strain Wis 54-1255 (Backus \& Stauffer, 1955; Stauffer, 1961). Under standard conditions in our laboratory (Macdonald, Hutchinson \& Gillett, 1963 $a$ ) it produced more than twenty times the amount of penicillin yielded by its ancestral strain, NRRL 1951. Between strains NRRL 1951 and Wis 54-1255 there were 17 selection stages, 8 of which were preceded by mutagenic treatment (Fig. 1). As distinct from its immediate usefulness, it was believed that if a heterozygous diploid could be formed between these strains of remote relationship there should be no impediment to their successful formation between strains of similar or less distant relationshipsan essential preliminary to the examination of genetic differences between any pair of strains via the parasexual mechanism.

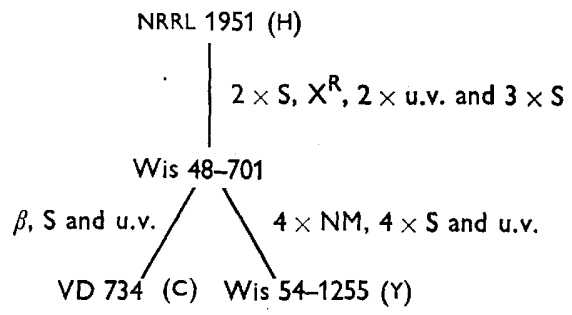

Fig. 1. Genealogy of strains of Penicillium chrysogenum. The domestic codes of the strains used here are shown in parentheses. $S=$ selection without mutagenic treatment, $\mathrm{X}^{\mathrm{R}}=$ selection following $\mathrm{X}$-ray treatment, $\beta=$ selection following $\beta$-irradiation, u.v. = selection following ultraviolet irradiation, NM = selection following nitrogenmustard treatment. The number of selection steps is shown where applicable, e.g. $4 \times \mathrm{NM}=$ four successive NM treatments.

Subsequent to their being labelled with suitable genetical markers it was found possible to synthesize a heterozygous diploid between strains NRRL 1951 and Wis 541255. Two diploids were also synthesized between suitably labelled mutants of the former and of strain vD 734, which was similar in penicillin yield to Wis 54-1255 but of different lineage (see Fig. 1). Segregants were examined which were presumed to arise from the three diploids by parasexual processes.

\section{METHODS}

Details of media, methods and nomenclature are given in Macdonald, Hutchinson \& Gillett $(1963 a, b)$. Only methods specific to the work featured here are given below.

Strains. The parental strains were as follows (their domestic codes are shown in parentheses): vD 734(c), NRRL 1951 (H), Wis 54-1255(y) (see Fig. 1). These are referred to as 'original' parents. The lineages of mutants of them used for diploid syntheses are given below (the latter, termed 'immediate' parents, were obtained following successive ultraviolet treatments of strains $\mathrm{C}, \mathrm{H}$ and $\mathrm{Y}$ ):

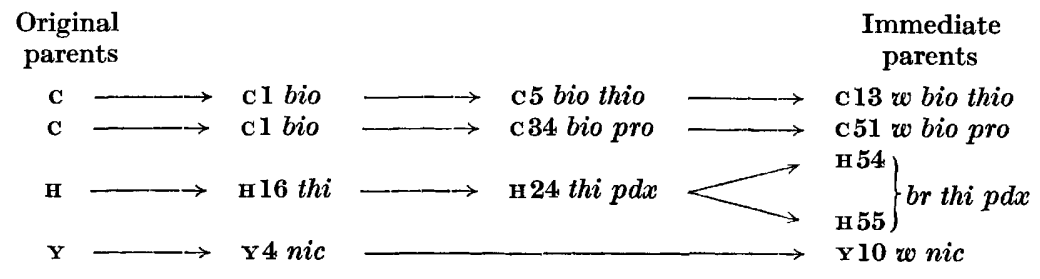


Unless otherwise indicated the strains were green-spored and prototrophic. The abbreviations used above mean as follows: $b i o=$ biotin, $b r=$ brown spores, nic $=$ nicotinamide, $p d x=$ pyridoxin, pro $=$ proline, $t h i=$ thiamine, thio $=$ thiosulphate, $w=$ white spores.

Strains н 54 and $\mathrm{H} 55$ were independent isolates from strain $\mathrm{H} 24$, both with brown spores. When isolated strains $\mathrm{C} 51$ and $\mathrm{H} \mathbf{5 4}$ were shown to retain or nearly retain the penicillin yield of their original parents, strain $\mathrm{H} 55$ appeared slightly superior in yield to strain $\mathrm{H}$, while strains $\mathrm{C} 13$ and $\mathrm{y} 10$ were substantially lower in penicillin yield than their parental strains, $c$ and $y$ (Table 2). In the case of strains c13 and y 10 the loss of penicillin titre occurred in the former during the selection step from $\mathrm{c} 1$ to $\mathrm{c} 5$ and in the latter during the selection step from $\mathrm{Y}$ to $\mathrm{y} 4$.

Isolation of heterozygous diploids. Heterokaryons were synthesized, by the method described by Macdonald et al. $(1963 b)$, between brown- and white-sporingauxotrophs. Mutations affecting spore colour had cell-localized action (Pontecorvo, 1946) so that a heterokaryon produced conidia of each colour except subsequent to heterozygous diploidization when nuclei descended from such an event gave rise to green conidia. In the case of Diploid 1, $9 \times 10^{6}$ conidia from a heterokaryon were plated on minimal medium (MM) agar and $\mathbf{5 0 0}$ green colonies grew; one was purified by single colony isolation to serve as stock culture. Diploids 2 and 7 were isolated from green sectors on heterokaryons and purified by single colony isolation (Table 1 ).

Isolation and testing of segregants. Diploid conidia were plated on complete medium (CM) agar to allow the growth of discrete colonies. When these had spored well, normally after 7 days of incubation, they were examined macroscopically for sectors, or patches, of white or brown conidia and also under a binocular microscope for subvisible mutant spore colour patches. Not more than one patch or sector of either colour was taken from any single diploid colony. Conidia were removed from a sector or patch of mutant spore colour and streaked on CM agar for purification. A single colony was isolated on to a CM agar slope and on to a marked position on a CM agar 'master' plate which accommodated 26 such isolates. Isolates made in this way were termed 'first-order' segregants (Pontecorvo, Roper \& Forbes, 1953). Using a multi-inoculating device and following methods similar to those used by Pontecorvo et al. (1953) the segregants were scored for auxotrophic markers.

Estimates of ploidy by spore measurement. Cultures grown on CM agar for 12 days at $25^{\circ}$ were used as sources of conidia in initial measurements made to investigate the relative sizes of conidia from the various parental strains and synthesized diploids. Conidia were collected in $20 \%$ lysol (v/v; Pontecorvo, Tarr Gloor \& Forbes, 1954) and measured along their longest axis to the nearest $0 \cdot 25 \mu$. Individual measurements were made of 100 conidia for each parent and diploid strain, but not normally of more than 20 for segregants.

\section{RESULTS}

Conidia of Penicillium chrysogenum strains $\mathrm{C}, \mathrm{H}$ and $\mathrm{y}$ are presumed to be haploid and uninucleate mainly on the evidence that their mutation rates to auxotrophy are similar to each other and to those of conidia of a related fungus, Aspergillus nidulans, whose conidia are known to be haploid and uninucleate (Pontecorvo, Roper, Hemmons, Macdonald \& Bufton, 1953). However, spore measurements given in Table 1 show a variability between strains $\mathrm{c}, \mathrm{H}$ and $\mathrm{y}$. Because of such variability, 


\section{K. D. Macdonald, J. M. Hutchinson and W. A. Gillett}

the difficulties of using spore size in $\boldsymbol{P}$. chrysogenum as a criterion of haploidy or diploidy have already been pointed out by Pontecorvo \& Sermonti (1954), although in later work Sermonti $(1956,1959 a)$ made use of spore size as a diagnostic test for ploidy estimation. Since spore measurements of Diploids 1 and 2 are significantly higher than any of their parental strains then haploid and diploid segregants from these diploids ought to be distinguishable by conidial size (Table 1). However, in diploid 7, although its conidia are significantly larger than those from either immediate parent and from the original parental strain $\mathrm{H}$, they are similar in size to those from parental strain c (Table 1). It is presumed that segregant haploids of this latter type could not be differentiated from Diploid 7 by conidial size. When heterozygous diploids are synthesized, the ability to recognize haploid from diploid segregants by spore measurement has probably to be assessed anew in each particular case by comparisons of spore sizes as between the parental and diploid strains.

Table 1. Sizes of conidia from the original and immediate parents of Diploids 1, 2 and 7 and of conidia from these three Penicillium chrysogenum diploids

In the case of each strain, measurements were made of 100 individual conidia along their longest axes.

\begin{tabular}{|c|c|c|c|c|c|c|c|c|}
\hline \multicolumn{3}{|c|}{ Original parental strains } & \multicolumn{3}{|c|}{ Immediate parental strains } & \multicolumn{3}{|c|}{ Heterozygous diploids } \\
\hline Code & $\begin{array}{c}\text { Mean } \\
\text { diam. } \\
(\mu)\end{array}$ & $\begin{array}{l}95 \% \text { fiducial } \\
\text { limits of } \\
\text { mean }\end{array}$ & Code & $\begin{array}{c}\text { Mean } \\
\text { diam. } \\
(\mu)\end{array}$ & $\begin{array}{r}95 \% \text { fiducial } \\
\text { limits of mean }\end{array}$ & Code & $\begin{array}{c}\text { Mean } \\
\text { diam. }\end{array}$ & $\begin{array}{l}95 \% \text { fiducial } \\
\text { limits of mean }\end{array}$ \\
\hline $\begin{array}{l}\mathbf{H} \\
\mathbf{Y}\end{array}$ & $\begin{array}{l}3 \cdot 14 \\
4 \cdot 20\end{array}$ & $\begin{array}{l}3 \cdot 04-3 \cdot 24 \\
4 \cdot 03-4 \cdot 37\end{array}$ & $\begin{array}{l}\text { H } 54 \\
\text { Y } 10\end{array}$ & $\begin{array}{l}3 \cdot 59 \\
4 \cdot 38\end{array}$ & $\begin{array}{l}3 \cdot 47-3 \cdot 71 \\
4 \cdot 26-4 \cdot 51\end{array}$ & 1 & $4 \cdot 66$ & $4 \cdot 59-4.73$ \\
\hline $\begin{array}{l}\mathbf{H} \\
\mathbf{C}\end{array}$ & $\begin{array}{l}3 \cdot 14 \\
4 \cdot 40\end{array}$ & $\begin{array}{l}3 \cdot 04-3 \cdot 24 \\
4 \cdot 27-4 \cdot 53\end{array}$ & $\begin{array}{l}\text { H } 54 \\
\text { C } 13\end{array}$ & $\begin{array}{l}3 \cdot 59 \\
4 \cdot 30\end{array}$ & $\begin{array}{l}3 \cdot 47-3 \cdot 71 \\
4 \cdot 13-4 \cdot 46\end{array}$ & 2 & $4 \cdot 82$ & $4.71-4.93$ \\
\hline $\begin{array}{l}\text { H } \\
\text { C }\end{array}$ & $\begin{array}{l}3 \cdot 14 \\
4 \cdot 40\end{array}$ & $\begin{array}{l}3 \cdot 04-3 \cdot 24 \\
4 \cdot 27-4 \cdot 53\end{array}$ & $\begin{array}{l}\text { H } 55 \\
\text { C51 }\end{array}$ & $\begin{array}{l}3 \cdot 21 \\
4 \cdot 05\end{array}$ & $\begin{array}{l}3 \cdot 14-3 \cdot 27 \\
3 \cdot 90-4 \cdot 20\end{array}$ & 7 & $4 \cdot 32$ & $4 \cdot 22-4 \cdot 41$ \\
\hline
\end{tabular}

Among the five genetically labelled strains used as immediate parents for diploid syntheses, two were considerably lower in penicillin yield than their original parents; these were strains C13 and y 10 (Table 2). Previous work has shown that low titre which arose concomitantly with auxotrophic mutation was most likely the effect of pleiotropy at the auxotrophic locus (Macdonald et al. 1963a). The low yields of strains $\mathrm{C} 13$ and y 10 can therefore probably be attributed to the mutations responsible for their thiosulphate and nicotinamide requirements, respectively. In the case of strain c13, there is additional evidence to support this (Macdonald et al. 1963a). As surmised from the prototrophic nature of the three diploids, the nutritional effects of the auxotrophic markers used in our work were recessive. It would perhaps be reasonable to expect that the pleiotropic effects of nutritional mutations on penicillin yield were also recessive, although confirmation would be desirable; comparison of the results from Diploids 2 and 7 helps in this direction (Table 2). These had the same original parents, strains $\mathrm{c}$ and $\mathrm{H}$, and, of the four immediate parents, only one, strain $\mathbf{c 1 3}$, showed a marked decrease in penicillin yield as a consequence of genetic labelling. Both Diploids 2 and 7 had relatively low penicillin titres. Since Diploid 7 was formed from immediate parents whose yields were not substantially affected by labelling mutations, the results suggest that the mutations leading to increased penicillin yield in strain $\mathrm{c}$ are mostly, if not all, recessive. It 
follows that the low titre of Diploid 2 can also be explained on this basis and that the recessive nature of the pleiotropic effect on penicillin yield of the thio marker in strain c13 can be more confidently assumed. The low penicillin yield of Diploid 1 is also most likely due to the recessiveness of mutations accumulated in strain $\mathbf{Y}$.

Table 2. Penicillin yields of heterozygous diploids of Penicillium chrysogenum and of the strains from which they were derived

Penicillin was determined by biological assay after fermentation for 6 days. The results for each strain were averaged from at least six separate fermentations and are given in units/ml.

\begin{tabular}{|c|c|c|c|c|c|c|c|c|}
\hline \multicolumn{3}{|c|}{ Original parental strains } & \multicolumn{3}{|c|}{ Immediate parental strains } & \multicolumn{3}{|c|}{ Heterozygous diploids } \\
\hline Code & $\begin{array}{c}\text { Mean } \\
\text { titre }\end{array}$ & $\begin{array}{l}95 \% \text { fiducial } \\
\text { limits of mean }\end{array}$ & Code & $\begin{array}{l}\text { Mean } \\
\text { titre }\end{array}$ & $\begin{array}{l}95 \% \text { fiducial } \\
\text { limits of mean }\end{array}$ & Code & $\begin{array}{c}\text { Mean } \\
\text { titre }\end{array}$ & $\begin{array}{l}95 \% \text { fiducial } \\
\text { limits of mean }\end{array}$ \\
\hline $\begin{array}{l}\mathbf{H} \\
\mathbf{Y}\end{array}$ & $\begin{array}{r}115 \\
3410\end{array}$ & $\begin{array}{c}110-120 \\
3180-3630\end{array}$ & $\begin{array}{l}\text { H } 54 \\
\text { Y } 10\end{array}$ & $\begin{array}{l}105 \\
945\end{array}$ & $\begin{array}{c}90-120 \\
830-1060\end{array}$ & 1 & 280 & $240-320$ \\
\hline $\begin{array}{l}\mathbf{H} \\
\mathbf{C}\end{array}$ & $\begin{array}{r}115 \\
3110\end{array}$ & $\begin{array}{c}110-120 \\
2980-3240\end{array}$ & $\begin{array}{l}\text { H 54 } \\
\text { C } 13\end{array}$ & $\begin{array}{l}105 \\
375\end{array}$ & $\begin{array}{r}90-120 \\
290-460\end{array}$ & 2 & 115 & 100-130 \\
\hline $\begin{array}{l}\mathbf{H} \\
\mathbf{C}\end{array}$ & $\begin{array}{r}115 \\
3110\end{array}$ & $\begin{array}{c}110-120 \\
2980-3240\end{array}$ & $\begin{array}{l}\text { H } 55 \\
\text { C51 }\end{array}$ & $\begin{array}{r}170 \\
3290\end{array}$ & $\begin{array}{c}150-190 \\
2775-3810\end{array}$ & 7 & 175 & $160-190$ \\
\hline
\end{tabular}

Although the penicillin yields of all three diploids are very much closer to that of strain $\mathrm{H}$ than to those of strains $\mathrm{c}$ and $\mathrm{y}$, thus suggesting the dominating effect of the $\mathrm{H}$ strain genome, all three diploids differ significantly in yield one from another (Table 2). If only recessive mutations responsible for increased yield in strains $\mathrm{c}$ and $\mathrm{Y}$ had to be taken into account then all the diploids should have the yield of strain H. In Diploids 2 and 7 the penicillin yields was that of the lowest immediate parent. The change in strain $\mathbf{H} 5 \mathbf{5}$ which led to an increase in titre over its parental strain $\mathbf{H}$ could be dominant or, if recessive, be already present in strain $\mathbf{c}$ (Table 2). Diploid $\mathbf{I}$ is the highest yielder of all three. During storage, strain $\mathbf{H}$ could have accumulated one or more mutations deleterious to penicillin titre which were recessive and thus masked in Diploid 1. The lack of a similar effect in Diploids $\mathbf{2}$ and $\boldsymbol{7}$ could be the result of strain $\mathrm{c}$ having the deleterious mutation or mutations carried by strain $\mathrm{H}$.

From all three diploids the proportion of brown-sporing greatly exceeds that of white-sporing segregants (Table 3); furthermore, as estimated by spore measurement, haploid segregants occurred much more frequently than diploid segregants. Two observations support the measurement diagnosis of haploidy. In Diploid 7 , first-order segregants which measure haploid, have brown spores and require thiamine and pyridoxin for growth, are hardly likely to be diploid unless the three independently obtained genetic markers are on the same arm of one chromosome (Pontecorvo \& Kafer, 1958). Also, all the brown-sporing segregants measuring haploid had conidia of the $\mathrm{H}$ strain type, rather than of the $\mathrm{C}$ or $\mathrm{Y}$ strain type (see Table 1). These conidia were relatively easy to assess as haploids, by measurement, because of their small size.

Growth-rate measurements shown in Table $4 \mathrm{~A}$ were made on a small sample of first-order segregants from Diploid 1. While growth rates on CM agar do not necessarily reflect rates of nuclear multiplication in the cytoplasm it is interesting to note that there is a correlation between growth rates and the frequency at which different segregant types were isolated from Diploid 1 (Tables 3, 4A). A larger 
K. D. Macdonald, J. M. Hutchinson and W. A. Gullett
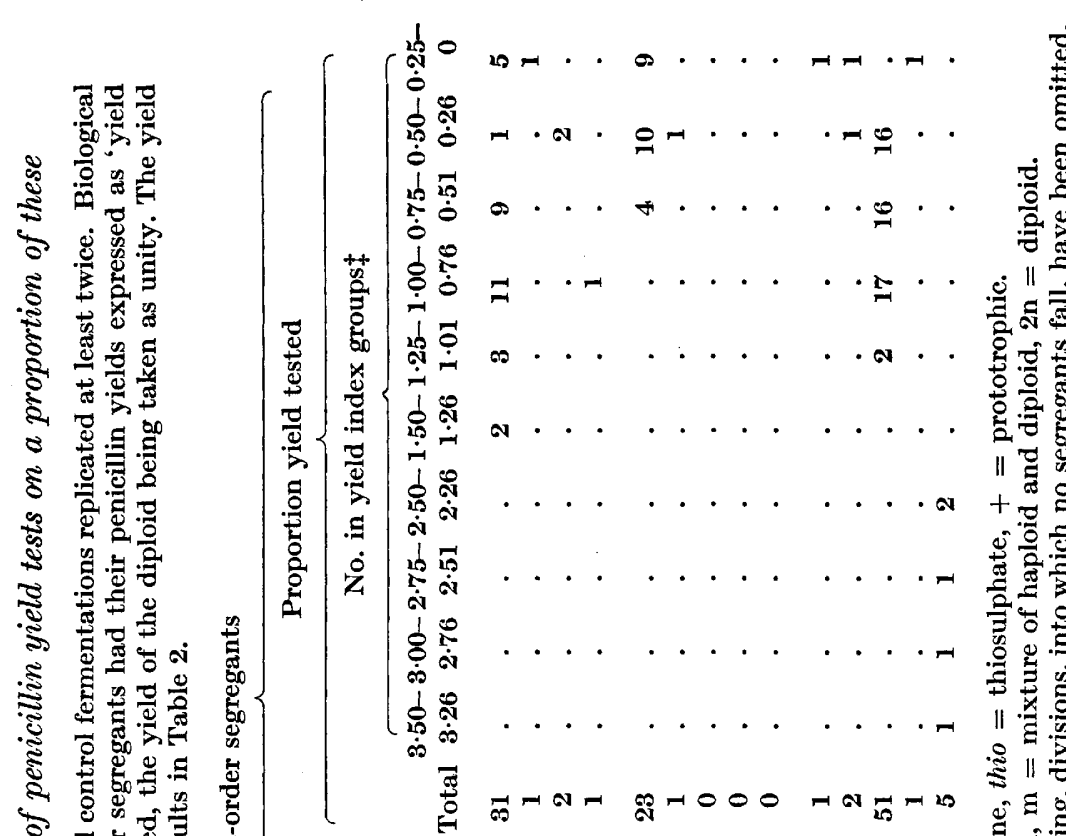

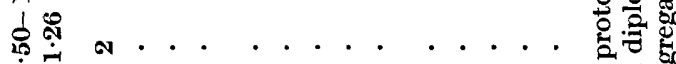

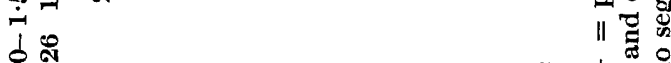

内人

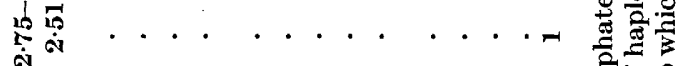

की .....

ติ

的而

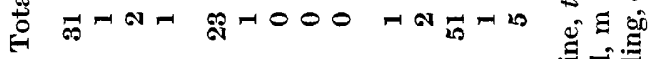

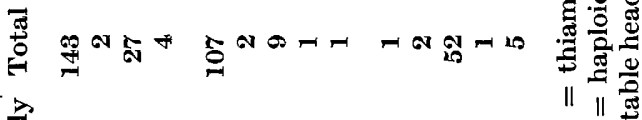

苟焉总

实客家

需

영의 궁

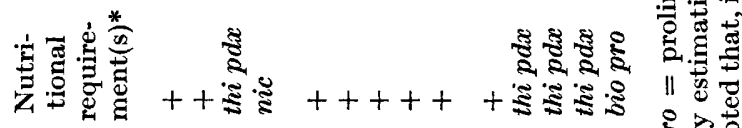

ก ซ

ชู.

온

今

है

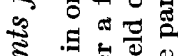

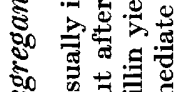

कू क्ञ

む

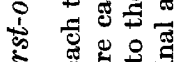

运 迎

ค

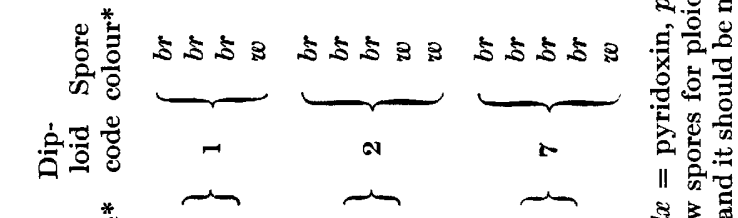

웅

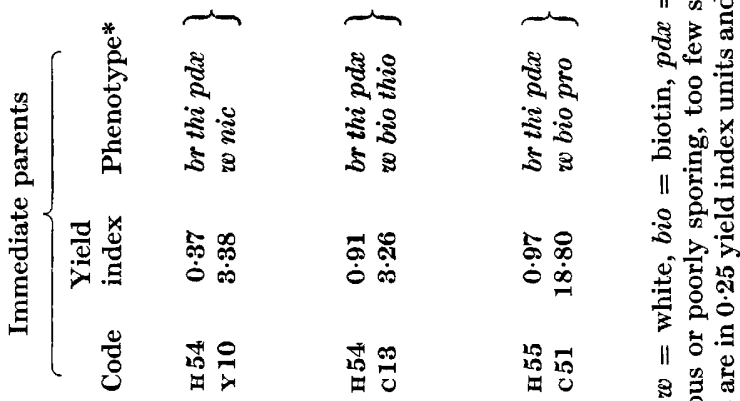

을 总

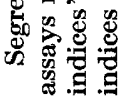

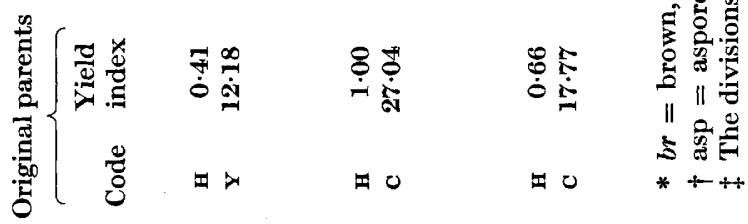


proportion of $b r$ prototrophs may have been isolated because they had a selective advantage in the cytoplasm. Strain $\mathbf{H}$ grew faster and spored more thickly than either strain $\mathrm{C}$ or strain Y (Pl. 1; Table 4B). Another advantage which br segregants might enjoy was that they might have the sporulation characteristics of strain $\mathbf{H}$, which would make them easier to detect by the method of segregant isolation used.

Segregants from Diploids 1 and 2 included $b r$ prototrophic haploids (Table 3). Their lack among segregants from Diploid 7 could be explained if thi and $p d x$ were on the same chromosome, which the results do not contradict, and if the $\mathbf{c} 51$ w locus were on the homologue of the thi $p d x$ chromosome. If $w$ were epistatic to $b r$ then $b r$ prototrophic haploid segregants would not occur in Diploid 7 after first-order segregation.

Table 4. Growth rates of parental and heterozygous diploid strains of Penicillium chrysogenum and first-order segregants from Diploid 1

Fifteen ml. amounts of CM agar were added to Petri dishes of $3 \frac{1}{2}$ in. diameter and conidia inoculated in the centre of these plates so that a single colony developed on each plate. Incubation was at $\mathbf{2 5}^{\circ}$. Each colony was allowed to grow for 3 days before measurements began. In the case of each strain measurements were made of the advance of a colony edge in a period of $48 \mathrm{hr}$. Except as shown below the results for each strain are the average of 18 such observations. The exceptions were Diploid 2 and segregant 1/4-7, 12 observations each, and strains $\mathrm{H} 54$ and $\mathrm{H} 55,6$ observations each. The results in Table $4 \mathrm{~A}$ and $4 \mathrm{~B}$ were from two separate experiments done at different times and are therefore not strictly comparable.

\section{A. First-order segregants from Diploid 1}

\begin{tabular}{|c|c|c|c|c|c|}
\hline \multirow[b]{2}{*}{ Code } & \multicolumn{2}{|c|}{ Phenotype* } & \multirow{2}{*}{$\begin{array}{l}\text { Ploidy† as } \\
\text { estimated } \\
\text { by spore } \\
\text { measurement }\end{array}$} & \multirow{2}{*}{$\begin{array}{c}\text { Mean of } \\
\text { growth } \\
\text { measurements } \\
\text { (mm.) }\end{array}$} & \multirow[b]{2}{*}{$\begin{array}{l}95 \% \text { fiducial } \\
\text { limits of mean }\end{array}$} \\
\hline & $\begin{array}{l}\text { Spore } \\
\text { colour }\end{array}$ & $\begin{array}{c}\text { Nutritional } \\
\text { requirement(s) }\end{array}$ & & & \\
\hline $1 / 1-8$ & $b r$ & + & $\mathbf{n}$ & $2 \cdot 91$ & $2 \cdot 71-3 \cdot 10$ \\
\hline $1 / 1-26$ & $b r$ & + & $\mathbf{n}$ & $3 \cdot 85$ & $3 \cdot 68-4 \cdot 02$ \\
\hline $1 / 1-11$ & $b r$ & thi $p d x$ & $\mathbf{n}$ & $2 \cdot 49$ & $2 \cdot 22-2 \cdot 76$ \\
\hline $1 / 1-12$ & $b r$ & $t h i p d x$ & $\mathbf{n}$ & $2 \cdot 67$ & $2 \cdot 38-2 \cdot 95$ \\
\hline $1 / 4-7$ & $b r$ & thi $p d x$ & $\mathbf{n}$ & $2 \cdot 83$ & $2 \cdot 45-3 \cdot 20$ \\
\hline $1 / 4-9$ & $b r$ & thi $p d x$ & $\mathbf{n}$ & $2 \cdot 22$ & $2 \cdot 02-2 \cdot 42$ \\
\hline $1 / 5-12$ & $b r$ & thi $p d x$ & $\mathrm{~m}$ & $2 \cdot 41$ & $2 \cdot 13-2 \cdot 69$ \\
\hline $1 / 7-21$ & $w$ & nic & $\mathrm{n}$ & $2 \cdot 12$ & $1 \cdot 96-2 \cdot 29$ \\
\hline
\end{tabular}

$* b r=$ brown, $w=$ white,$+=$ prototrophic, $n i c=$ nicotinamide, $p d x=$ pyridoxin, $t h i=$ thiamine.

$\dagger \mathbf{n}=$ haploid, $\mathbf{m}=$ mixture of haploid and diploid.

\section{B. Parental and heterozygous diploid strains}

\begin{tabular}{|c|c|c|c|c|c|c|c|c|}
\hline \multicolumn{3}{|c|}{ Original parents } & \multicolumn{3}{|c|}{ Immediate parents } & \multicolumn{3}{|c|}{ Heterozygous diploids } \\
\hline Code & $\begin{array}{c}\text { Mean } \\
\text { of } \\
\text { growth } \\
\text { measure- } \\
\text { ments } \\
\text { (mm.) }\end{array}$ & $\begin{array}{c}95 \% \\
\text { fiducial } \\
\text { limits } \\
\text { of mean }\end{array}$ & Code & $\begin{array}{c}\text { Mean } \\
\text { of } \\
\text { growth } \\
\text { measure- } \\
\text { ments } \\
\text { (mm.) }\end{array}$ & $\begin{array}{c}95 \% \\
\text { fiducial } \\
\text { limits } \\
\text { of mean }\end{array}$ & Code & $\begin{array}{l}\text { Mean } \\
\text { of } \\
\text { growth } \\
\text { measure- } \\
\text { ments } \\
\text { (mm.) }\end{array}$ & $\begin{array}{l}95 \% \\
\text { fiducial } \\
\text { limits } \\
\text { of mean }\end{array}$ \\
\hline $\begin{array}{l}\mathbf{H} \\
\mathbf{Y}\end{array}$ & $\begin{array}{l}5 \cdot 17 \\
2 \cdot 90\end{array}$ & $\begin{array}{l}4 \cdot 97-5 \cdot 38 \\
2 \cdot 77-3 \cdot 03\end{array}$ & $\begin{array}{l}\text { H 54 } \\
\text { Y } 10\end{array}$ & $\begin{array}{l}4 \cdot 30 \\
2 \cdot 35\end{array}$ & $\begin{array}{l}3 \cdot 90-4 \cdot 70 \\
2 \cdot 11-2 \cdot 59\end{array}$ & 1 & $4 \cdot 94$ & $4 \cdot 73-5 \cdot 16$ \\
\hline $\begin{array}{l}\mathbf{H} \\
\mathbf{C}\end{array}$ & $\begin{array}{l}5 \cdot 17 \\
2 \cdot 04\end{array}$ & $\begin{array}{l}4 \cdot 97-5 \cdot 38 \\
1 \cdot 90-2 \cdot 19\end{array}$ & $\begin{array}{l}\text { н } 54 \\
\text { C } 13\end{array}$ & $\begin{array}{l}4 \cdot 30 \\
1 \cdot 84\end{array}$ & $\begin{array}{l}3 \cdot 90-4 \cdot 70 \\
1 \cdot 72-1 \cdot 96\end{array}$ & 2 & $4 \cdot 49$ & $4 \cdot 22-4.77$ \\
\hline $\begin{array}{l}\mathbf{H} \\
\mathbf{C}\end{array}$ & $\begin{array}{l}5 \cdot 17 \\
2 \cdot 04\end{array}$ & $\begin{array}{l}4 \cdot 97-5 \cdot 38 \\
1 \cdot 90-2 \cdot 19\end{array}$ & $\begin{array}{l}\text { H } 55 \\
\text { c51 }\end{array}$ & $\begin{array}{l}4.53 \\
1.24\end{array}$ & $\begin{array}{l}4 \cdot 28-4 \cdot 77 \\
1 \cdot 07-1 \cdot 41\end{array}$ & 7 & $5 \cdot 18$ & $4 \cdot 89-5 \cdot 46$ \\
\hline
\end{tabular}




\section{K. D. Macdonald, J. M. Hutchinson and W. A. Gillett}

When segregants from Diploid 7 were observed for chrysogenin production, all those with brown spores produced this pigment, but no detectable amounts were produced by those with white spores. Taking these results in conjunction with previous evidence (Macdonald et al. $1963 \mathrm{~b}$ ), it appeared that the ability to produce chrysogenin was under chromosomal control and, since Diploid 7 also produced chrysogenin, that this ability was not a recessive trait.

The appearance of each of the three heterozygous diploids and of their original and immediate parent strains is shown in $\mathrm{Pl} .1$.

\section{DISCUSSION}

The preponderance of haploids among those segregants isolated from Diploids 1, 2 and 7 might suggest that the spore colour markers were closely linked to their centromeres, at least in the case of strains $\mathbf{5 4}$ and $\mathrm{H} \mathbf{5 5}$, since $b r$ haploids formed the majority of segregants (Table 3). Another possibility is that the component haploid genomes of each diploid differ to an extent whereby effective synapsis of chromosomes leading to viable cross-over products was infrequent. Strains C and y were derived from strain $\mathrm{H}$ after several stages of selection and these steps included those in which mutagenic treatment was used (see Fig. 1). Strains $\mathrm{C}$ and $\mathrm{y}$ could therefore include chromosomal rearrangements which made the recovery of cross-overs difficult in diploids synthesized between them and strain H. For example, in a nucleus heterozygous for a paracentric inversion, if during mitosis crossing-over occurred within the inverted region this would presumably lead to the production of monosomics, when division was equational for cross-over and non-cross-over. If this occurred in Penicillium chrysogenum then it would be expected that monosomics would break down to haploids (Pontecorvo \& Kafer, 1958; Kafer, 1961). While an inversion in one parental strain could suppress the occurrence of diploid recombinants showing crossing-over within the inverted region of chromosome, recombination between whole chromosomes could take place; in effect, haploid segregation would occur at the expense of diploid segregation.

A nuclear genetic model has already been suggested to account for the absence of prototrophic haploid $b r$ segregants from Diploid 7 (Table 3). Another possibility thought worth probing was an influence on segregant selection exerted through the cytoplasm.

Growth rate in fungi can be inherited through the cytoplasm (Jinks, 1956, 1957) so it is of interest to note that significant differences in growth rate exist between Diploids 2 and 7 (Table 4B). These diploids were made between the same original but different immediate parents. If labelling mutations in the immediate parents were recessive, and no nuclear segregation had taken place to affect growth rate, then cytoplasmic differences could account for these results. Growth rates increased in the order Diploid 2, Diploid 1 and Diploid 7 (Table 4B); this is the order in which the percentage of prototrophic $b r$ segregants decreased among the total number of br segregants in each diploid: $100 \%$ in Diploid 2; about $84 \%$ in Diploid 1; about $\mathbf{2} \%$ in Diploid 7 (Table 3 ). It is possible that $b r$ prototrophs might have less selective advantage under conditions of enhanced growth rate.

Diploid 2 produced sectors of increased growth rate morphologically similar to Diploid 7; one is illustrated in Pl. 1, fig. 1. Their origin is reminiscent of a similar phenomenon described by Sermonti (1959b) for Penicillium chrysogenum, where he 
presented evidence that such sectors were more likely to be due to cytoplasmic rather than to nuclear segregational events. From a Diploid 2 sector of increased growth rate, conidia were plated on CM agar and 52 brown-sporing segregants isolated by methods described earlier; all were prototrophic. Superficially this suggested that diploid growth rate had no obvious effect on the types and proportions of segregants which were isolated. The results paralleled those found when segregants were isolated from unsectored Diploid 2 colonies (Table 3). However, it is possible that in Diploid 2 the thi and $p d x$ alleles had been lost by a somatic segregation process, e.g. non-disjunction. Their segregation in Diploids 1 and 7 suggests that they may be on the same chromosome. The question of whether or not an influence on segregant selection is exerted through the cytoplasm must therefore remain open.

In Diploid 1, br prototrophic segregants whose conidia measure as haploid have a titre distribution the mode of which approximates to the penicillin yield of Diploid 1 (Table 3). If, as mentioned earlier, Diploid 1 had an increased yield over strain $\mathrm{H}$ because during storage the latter had collected one or more mutations deleterious to penicillin yield, then presumably these haploids do not carry these mutations.

All $b r$ segregants isolated from Diploid 2 were prototrophic and inferior in yield to the diploid. In Diploid $\%$, however, all $b r$ segregants which measured as haploid had requirements for thiamine and pyridoxin and ranged from types having the titre of Diploid 7 to those having about half this titre (Table 3). Diploids 2 and 7 were made between the same original parents (strains $\mathrm{H}$ and $\mathrm{c}$ ) so it is possible that the possession of the single chromosome on which it is inferred are the thi and $p d x$ alleles, or the lack of its homologue, can result in a maintenance of penicillin yield to that of the diploid value, when the former chromosome is in suitable combination with other chromosomes; the occurrence of low-yielding br thi pdx segregants from Diploid 7 makes this latter qualification necessary. This situation would arise if the homologue of the thi pdx chromosome carried one or more recessive mutations deleterious to penicillin yield and could explain the low yields of prototrophic segregants from Diploid 2. Segregants from Diploid 7 having the phenotype w bio pro have a higher titre value than the diploid, but lower than strain $\mathbf{c 5 1}$, the immediate parent whose phenotype they mimic. Their ploidy as estimated by measurement was doubtful, but if they were haploid they may have lost part of the $\mathrm{c} 51$ genome responsible for high yield.

No attempt was made to increase segregation by treatment with mutagenic agents (Ikeda, Ishitani \& Nakamura, 1957; Sermonti \& Morpurgo, 1959; Holliday, 1961). This was to avoid side effects of mutations which might have interfered with our analyses, including that of penicillin yields among segregants. However, in view of selective forces which may operate, the use of such agents may become essential to obtain a wider spectrum of segregant types. As Sermonti \& Morpurgo (1959) have pointed out, segregants which arise as the result of treating conidia should not be subjected to the action of intra-cytoplasmic selection.

Our gratitude is due to Dr D. W. Henderson, F.R.S., for his continued encouragement. We should also like to express our thanks to Professor J. A. Roper and Dr T. W. Burrows for useful discussion. We are grateful to Mr E. W. Harris and 


\section{K. D. Macdonald, J. M. Hutchinson and W. A. Gillett}

Miss Marion Stubbs, who have given expert technical assistance at different times. This work was financed by the National Research Development Corporation.

\section{REFERENCES}

Backus, M. P. \& Stauffer, J. F. (1955). The production and selection of a family of strains in Penicillium chrysogenum. Mycologia, 47, 429.

Holliday, R. (1961). Induced mitotic crossing-over in Ustilago maydis. Genet. Res. Camb. 2, 231.

IKEDA, Y., Ishitani, C. \& NAKAmura, K. (1957). A high frequency of heterozygous diploids and somatic recombination induced in imperfect fungi by ultra-violet light. J. gen. appl. Microbiol. Japan, 3, 1.

JINKS, J. L. (1956). Naturally occurring cytoplasmic changes in fungi. C.R. Lab. Carlsberg (Ser. physiol.), 26, 183.

Jinks, J. L. (1957). Selection for cytoplasmic differences. Proc. roy. Soc. B, 146, 527.

KAFER, E. (1961). The processes of spontaneous recombination in vegetative nuclei of Aspergillus nidulans. Genetics, 46, 1581.

Macdonald, K. D., Hutchinson, J. M. \& Gillett, W. A. (1963a). Isolation of auxotrophs of Penicillium chrysogenum and their penicillin yields. J. gen. Microbiol. 33, 365.

Macdonald, K. D., Hutchinson, J. M. \& Gillettr, W. A. (1963b). Heterokaryon studies and the genetic control of penicillin and chrysogenin production in Penicillium chrysogenum. J. gen. Microbiol. 33, 375.

Ponteconvo, G. (1946). Genetic systems based on heterokaryosis. Cold Spr. Harb. Symp. quant. Biol. 11, 193.

Ponteconvo, G. (1954). Mitotic recombination in the genetic systems of filamentous fungi. Caryologia, 4 (suppl.), 192.

Ponteconvo, G. \& Kafer, E. (1958). Genetic analysis by means of mitotic recombination. Advanc. Genet. 9, 71.

Pontecorvo, G., Roper, J. A. \& Forbes, E. (1953). Genetic recombination without sexual reproduction in Aspergillus niger. J. gen. Microbiol. 8, 198.

Pontecorvo, G., Roper, J. A., Hemmons, L. M., Macdonald, K. D. \& Bufton, A. W. J. (1953). The genetics of Aspergillus nidulans. Advanc. Genet. 5, 141.

Pontecorvo, G. \& Sermonti, G. (1954). Parasexual recombination in Penicillium chrysogenum. J. gen. Microbiol. 11, 94.

Pontecorvo, G., Tarr Gloor, E. \& Forbes, E. (1954). Analysis of mitotic recombination in Aspergillus nidulans. J. Genet. 52, 226.

Raper, K. B. \& Alexander, D. F. (1945). Penicillin. V. Mycological aspects of penicillin production. J. Elisha Mitchell sci. Soc. 61, 74.

SERmontr, G. (1956). Complementary genes which affect penicillin yields. J. gen. Microbiol. 15, 599.

Sermont, G. (1959a). Genetics of penicillin production. Ann. N.Y. Acad. Sci. 81, 950.

Sermonti, G. (1959b). Genetics of Penicillium chrysogenum. III. Cytoplasmic inheritance in Penicillium. Sel. Sci. Pap. Ist. sup. Sanit. 2, 407.

Sermonti, G. \& Morpurgo, G. (1959). Genetics of Penicillium chrysogenum. IV. Effects of certain mutagenic agents on somatic segregation from heterozygous diploids. Sel. Sci. Pap. Ist. sup. Sanit. 2, 416.

STAUFFer, J. F. (1961). The use of ultraviolet radiation for mutation in antibiotic producing fungi. Sci. Rep. Ist. sup. Sanit. 1, 472.

\section{EXPLANATION OF PLATE}

Figs. 1-3. In these three figures the appearances of the heterozygous diploids of Penicillium chrysogenum are shown, each with its immediate and original parents, after 10 days growth on $\mathrm{CM}$ agar at $25^{\circ}$. The scales are in centimetres. In fig. 2 the emergence of a sector from the Diploid 2 colony can be seen; this has a higher growth rate than the original colony. 

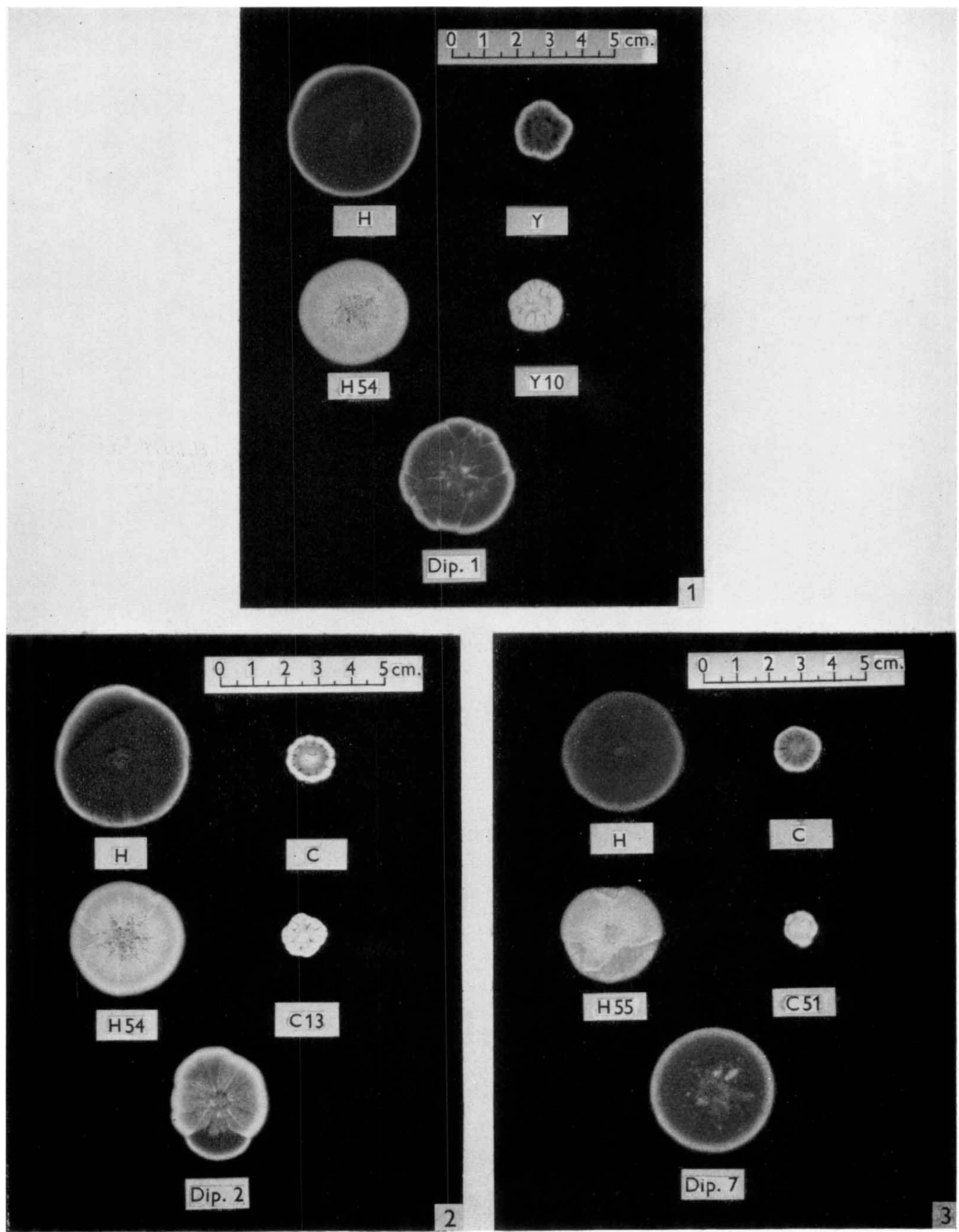

K. D. MaCDONALD, J. M. IIUTCIINSON AND W. A. GILLETT

(Facing p. 394) 